\title{
Design and Analysis of Quad-Band Rectangular Microstrip Patch Antenna
}

\author{
${ }^{1}$ Amit Kumar Gupta, ${ }^{2}$ R.K. Prasad and ${ }^{3}$ D. K. Srivastava \\ Department of Electronics and Communication Engineering \\ ${ }^{1,2}$ Madan Mohan Malaviya Engineering College, Gorakhpur, INDIA \\ ${ }^{3}$ Bundelkhand Institute Of Engineering \& Technology, Jhansi, INDIA
}

\begin{abstract}
This paper proposes the rectangular microstrip patch antenna suitable to operate in different frequency bands. The rectangular microstrip patch antenna is designed and simulated using IE3D simulation software. The result obtained shows that the designed antenna is suitable for operation in four different frequency bands with bandwidth of $6.90 \%, 2.33 \%, 12.02 \%$ and $2.74 \%$.The resonating behavior in different frequency bands makes this antenna structure suitable for different types of applications with an antenna gain of $5.509 \mathrm{dBi}$ and antenna efficiency of $89 \%$.
\end{abstract}

Keywords: Ground Plane, Microstrip Antenna, Patch Antenna, Probe Feed, Quad Band.

\section{Introduction}

Advancement in the technology leads to the miniaturization of the devices along with good performance capabilities. Same is the case with antenna technology, as the antenna technology is advancing day by day the small antenna size with good performance are in high demand. Several antenna structures such as yagi antenna, horn antenna, parabolic reflectors are used to fulfill these needs, but in some cases where two dimensional antennas are needed these antennas can't be used due to their bulky size and 3D structures, this is a case which leads to the requirement of $2 \mathrm{D}$ planer antenna and microstrip patch antenna is the most important type of planar antenna structure. There are several patch shapes which provides good bandwidth and gain for various applications.

Several researches has already been done to enhance the bandwidth and gain of the antenna, such as by using various shapes i.e. square, circular, elliptical shapes of the patch provides a good increment the bandwidth of the antenna. Some other researchers used stacked antenna configuration, antenna array etc. to enhance the gain and bandwidth of the antenna. These researches provide a good result in terms of gain and bandwidth but still these patch antennas can work up to a maximum of two to three frequency bands. Various applications need narrow bandwidth and some needs larger one. Similarly, some antenna need high gain and some needs lesser and if any antenna design is suitable enough to work in different frequency bands without changing its location and dimensions it will be an added advantage for the user.

\section{Research Methodology}

The research methodology inculcates the designing of the rectangular microstrip patch antenna. This designed antenna structure is fed by using single coaxial probe feed. After feeding the antenna structure these designed antennas are further simulated over IE3D simulation software, a MoM based simulation software. These simulations are continued till an optimum result is obtained.

\section{Antenna Design}

A rectangular microstrip patch antenna shown in fig. 1 is designed and simulated over IE3D. The dimensions are shown in fig. 1 along with in table 1.

Table 1

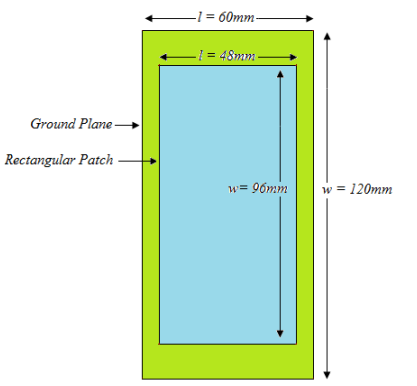

\begin{tabular}{|l|l|}
\hline Discription & Dimensions(in mm) \\
\hline Ground Plane & $l=60, w=120$ \\
\hline Patch & $l=48, w=96$ \\
\hline
\end{tabular}

Fig. 1 Design Of The Rectangular Microstrip Patch Antenna 


\section{Result and Discussion}

The simulation of this antenna structure provides good result and makes this antenna well suited to work in four different frequency bands.

The most important parameter to be analyzed is the bandwidth of the antenna and to analyze it the return loss curve is drawn and studied. The simulation of the antenna structure provides the return loss curve which is shown in fig. 2 .

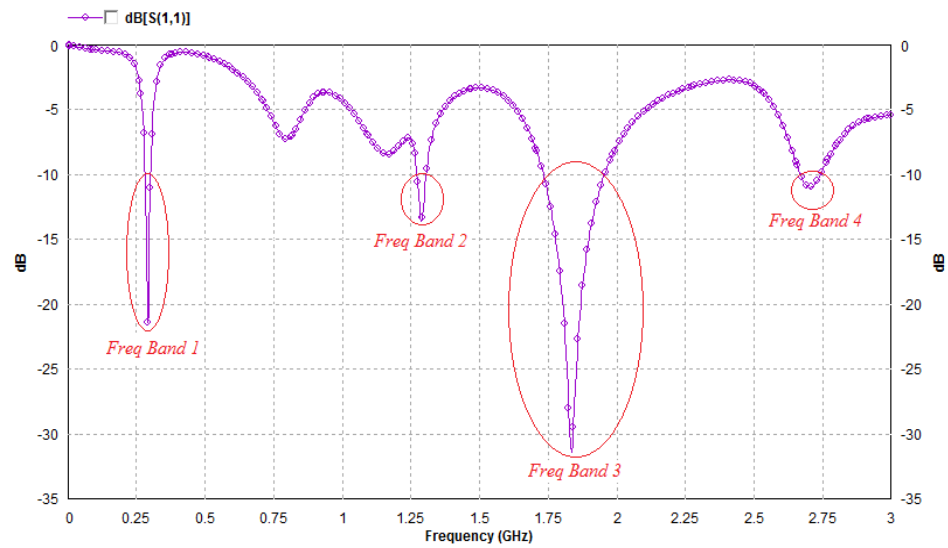

Fig. 2 Return Loss Curve Of The Designed Antenna Structure

Analyzing the curve shown in fig. 2 we can clearly mention four different frequency bands in which this rectangular patch antenna can work. Calculating the bandwidth of the antenna as shown in equation I, II, III and IV we can see the amount of bandwidth achieved in different frequency bands.

\section{Calculation of the bandwidth}

For frequency band 1

$f_{l 1}=0.282 \mathrm{GHz}, f_{h 1}=0.302 \mathrm{GHz}$,

$f_{r 1}=0.290 \mathrm{GHz}$

Bandwidth $_{1}=\frac{0.302-0.282}{0.290} \times 100=6.90 \%$

For frequency band 2

$f_{l 2}=1.272 \mathrm{GHz}, f_{h 2}=1.306 \mathrm{GHz}$,

$f_{r 2}=1.288 \mathrm{GHz}$

Bandwidth $_{2}=\frac{1.306-1.272}{1.288} \times 100=2.33 \%$

For frequency band 3

$f_{l 3}=1.733 \mathrm{GHz}, f_{h 3}=1.955 \mathrm{GHz}$,

$f_{r 3}=1.830 \mathrm{GHz}$

Bandwidth $=\frac{1.955-1.733}{1.830} \times 100=\mathbf{1 2 . 0 2} \%$

For frequency band 4

$f_{l 4}=2.668, f_{h 4}=2.742$,

$f_{r 4}=2.703$

Bandwidth ${ }_{4}=\frac{2.742-2.668}{2.703} \times 100=2.74 \%$

The curve shown in fig. 2 and the calculation done shows different amount of bandwidth at different frequency bands i.e. the bandwidth of $6.90 \%, 2.33 \%, 12.02 \%$ and $2.74 \%$ in different frequency bands which make this antenna structure suitable for four different types of applications.

Another most important parameter for the antenna is the gain of the antenna. The gain vs frequency curve obtained as a result of the simulation and shown in fig. 3 is used to calculate the gain of the antenna. 


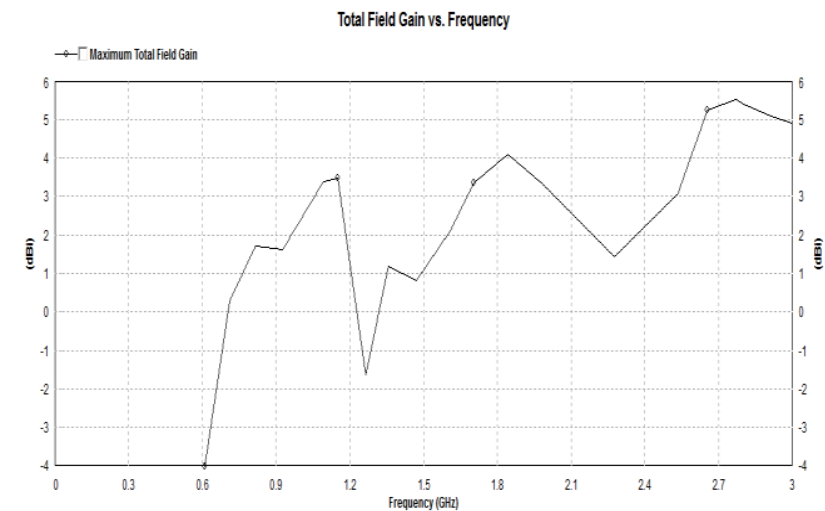

Fig. 3 Total Field Gain Vs Frequency Curve

The curve shown in fig. 3 shows a maximum gain of $5.509 \mathrm{dBi}$ at $2.769 \mathrm{GHz}$ frequency. Analysing the results shows that the amount of gain achieved is quite good for various applications.

Directivity is another important parameter of the antenna which is closely related to the antenna gain. To analyse the directivity of the antenna a curve between antenna directivity and frequency is shown in fig. 4.

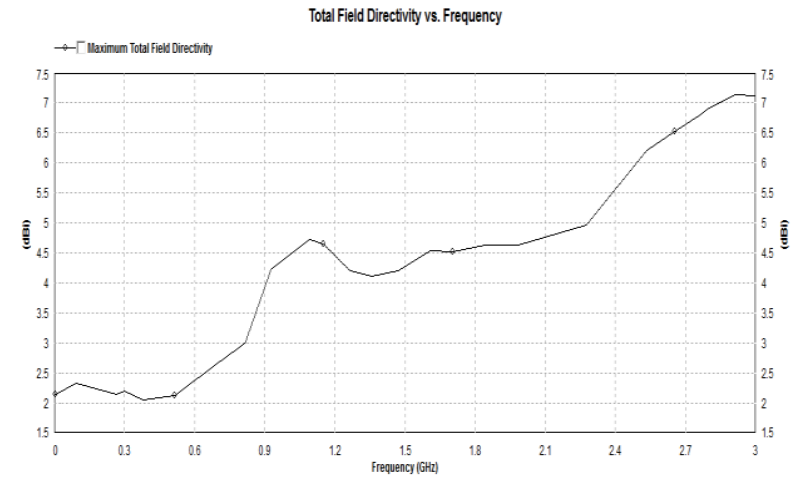

Fig. 4 Total Field Directivity Vs Frequency frequency.

The graph shown in fig. 4 shows a directivity having a maximum value of $7.145 \mathrm{dBi}$ at $2.914 \mathrm{GHz}$

Some other important parameters such as the VSWR of the antenna structure is shown in fig. 5. To make the antenna work properly the VSWR should be less than 2 for each frequency bands and the VSWR curve shown in fig. 5 shows a VSWR less than 2 in all four frequency bands.

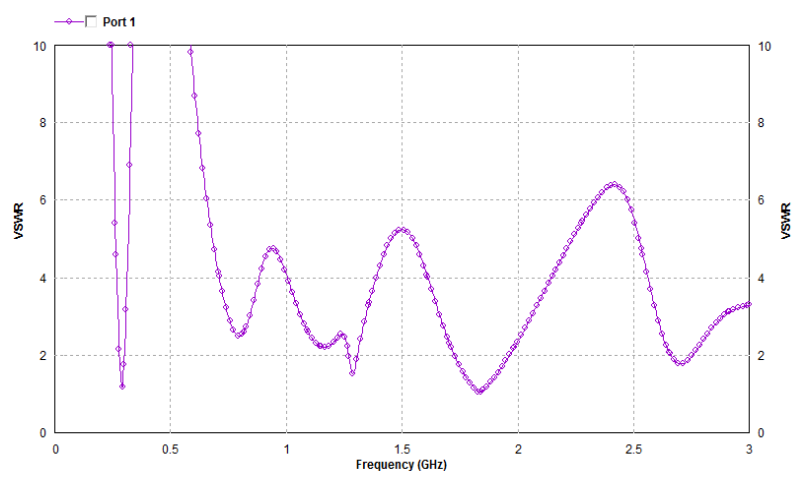

Fig. 5 VSWR Curve

Antenna efficiency and radiation efficiency are also very important terms and are used to analyse whether the antenna is efficient or not, similarly the radiation efficiency is used to analyse whether the antenna is radiating properly or not. The curves for antenna efficiency and radiation efficiency are shown in fig. 6 and fig. 7 respectively. 


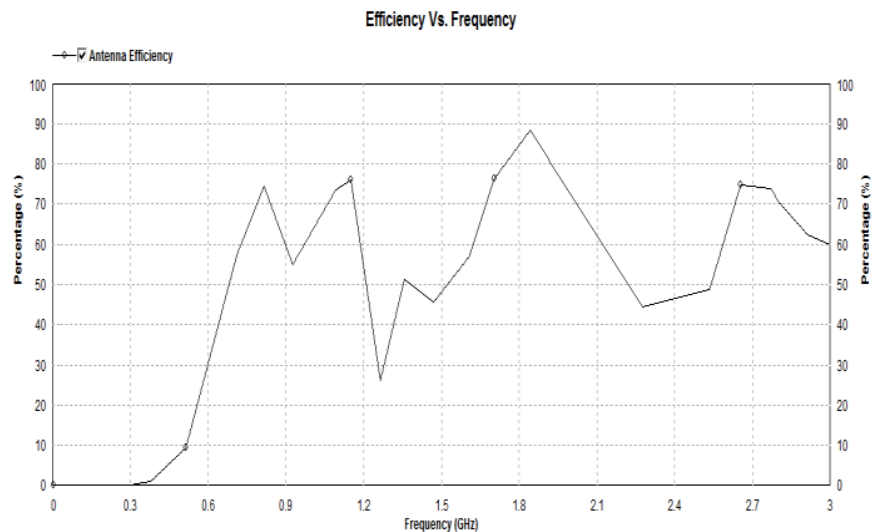

Fig. 6 Antenna Efficiency Vs Frequency

Analyzing the curve shown in fig. 6 and fig. 7 it can be clearly observed that the antenna structure designed provides an antenna efficiency of $88.270 \%$ at $1.84 \mathrm{GHz}$ frequency and the radiation efficiency of $95.14 \%$.

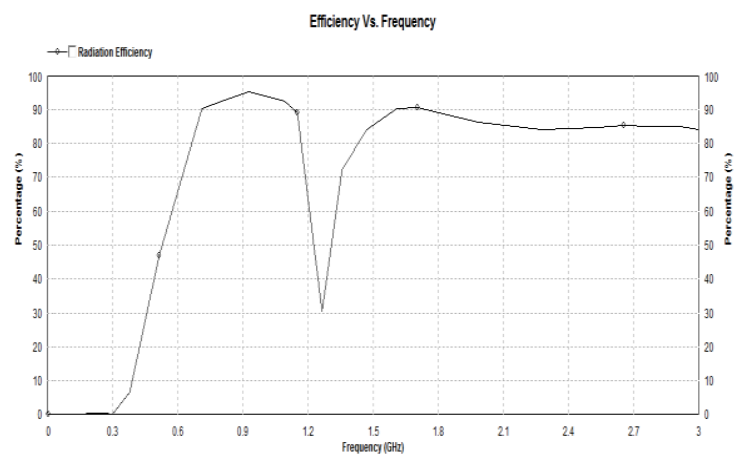

Fig. 7 Radiation Efficiency Vs Frequency

\section{Conclusion}

A rectangular microstrip patch antenna is designed and simulated over IE3D version 15.2. The designed antenna structure includes probe feeding method for the exciting the antenna. This antenna works in four different frequency bands as shown in the return loss curve, the bandwidth in all the four frequency bands are calculated and analysed. The antenna structure also provides a good amount of gain i.e. 5.509dBi and directivity i.e. $7.145 \mathrm{dBi}$. The antenna efficiency and the radiation efficiency of the designed antenna structure are about $90 \%$, which is good enough.

Analysing this type of structures we can further provide increment in the gain and bandwidth of the antenna.

\section{Acknowledgement}

The authors would like to express their sincere thanks to Electronics and Communication Engineering Department of M.M.M. Engineering College, Gorakhpur for providing the help to carry out this study and work.

\section{References}

[1] David M. Pozar, "Microstrip Antennas", Proceedings Of The IEEE, Vol. 80, No 1, p.p. 79-91, January 1992.

[2] Dalia Nashaat, Hala A. Elsadek, Esamt Abdallah, Hadia Elhenawy, and Magdy Iskander, "Ultra-wideband Co-planar Boat Microstrip Patch Antenna with Modified Ground Plane by Using Electromagnetic Band Gap Structure (EBG) for Wireless Communication", PIERS Proceedings, Moscow, Russia, p.p. 1052-1056, August 18-21, 2009.

[3] B.K. Ang and B.-K. Chung, "A Wideband E-Shaped Microstrip Patch Antenna For 5-6 Ghz Wireless Communications", Progress In Electromagnetics Research, PIER 75, p.p. 397-407, 2007.

[4] Moghe, P., Singhal, P.K., "Design Of A Single Layer L-Shaped Microstrip Patch Antenna", Emerging Trends in Electronic and Photonic Devices and Systems, 2009. ELECTRO '09. p.p. 307-309, 22-24 Dec. 2009.

[5] M. Jamshidifar, J. Nourinia, Ch. Ghobadi, and F. Arazm, "Wideband Fractal Butterfly Patch Antenna", Iranian Journal Of Electrical And Computer Engineering, Vol. 7, No. 2, p.p. 134-136, Summer-fall 2008.

[6] Vinod K. Singh, Zakir Ali, "Dual Band U-Shaped Microstrip Antenna For Wireless Communication", International Journal of Engineering Science and Technology, Vol. 2(6), p.p. 1623-1628, 2010.

[7] Ravi Kant, D.C.Dhubkarya, "Design and Analysis of H-Shape Microstrip Patch Antenna", Global Journal of Researches in Engineering, Vol. 10 Issue 6 (Ver 1.0), p.p. 26-29, November 2010.

[8] Mamdouh Gouda, Mohammed Y. M. Yousef, "A Novel Ultra Wide Band Yagi Microstrip Antenna For Wireless Applications", Journal of Theoretical and Applied Information Technology, p.p. 28-34, 2005 - 2010 JATIT and LLS. 
[9] L. Lolit Kumar Singh, Bhaskar Gupta, Partha P Sarkar, "Compact Circularly Polarized Microstrip Antenna with Slits on both Patch and Ground Plane”, IJECT Vol. 2, Issue 4, p.p. 77-80, ISSN : 2230-7109 (Online), ISSN : 2230-9543 (Print) Oct. - Dec. 2011.

[10] Tiwari, H. Kartikeyan, M.V., "Design Studies Of Stacked U-Slot Microstrip Patch Antenna For Dual Band Operation", Infrared Millimeter and Terahertz Waves (IRMMW-THz), 35th International Conference, p.p. 1-2, 5-10 Sept. 2010.

[11] Karim A. Hamad, "Design and Enhancement Bandwidth Rectangular Patch Antenna using Single Trapezoidal Slot Technique", ARPN Journal of Engineering and Applied Sciences, ISSN 1819-6608, Vol. 7, No. 3, p.p. 292-297, MARCH 2012.

[12] Elangovan, G. and J. Rajapaul Perinbam, "Wideband E-Shaped Microstrip Antenna for Wireless Sensor Networks", American Journal of Applied Sciences 9 (1) p.p. 89-92, ISSN 1546-9239 @) 2012 Science Publications, 2012.

[13] K. Rambabu, M. Alam, J. Bornemann and M. A. Stuchly, "Compact Wideband Dual-Polarized Microstrip Patch Antenna" IEEE Transaction, 2004.

[14] www.google.co.in

[15] http://ieeexplore.ieee.org/Xplore/guesthome.jsp

Authors:

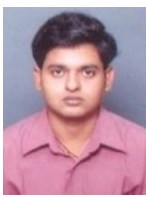

Amit Kumar Gupta has completed his B.Tech in Electronics and Communication Engineering from Pranveer Singh Institute of Technology, Kanpur in 2008. Currently he is pursuing his M.Tech in Digital Systems from Madan Mohan Malviya Engineering College, Gorakhpur. He has presented one paper in national conference and published one paper in international journal. His main areas of interest are Microstrip Patch Antenna, Wireless Sensor Network and Mobile Ad-hoc Network.

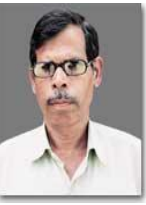

Ram Krishna Prasad has completed his B.Tech in Electronics and Communication Engineering from B.I.T Sindri, Dhanbad in 1980 and M.Tech in Electronic Instrumentation from IT-BHU in 1982. Currently he is pursuing his Phd. from IFTM University Moradabad. He is an Associate Professor in M. M. M. Engineering College, Gorakhpur since 1983. He has published seven papers in national and one paper in international journal. His main areas of interest are Microstrip Patch Antenna and Communication Engineering.

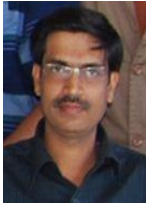

Dr. D. K. Srivastava is a Reader in the Department of Electronics and Communication Engineering, Bundelkhand Institute of Engineering and Technology Jhansi, India. He has more than 14 years of experience in teaching, research and administrative work. He is Ex Member IEEE. His current area of research includes Microwaves and Optical communication. He has published around fifteen papers in referred international journals. He has also presented more than thirty research articles in national and international conferences. 